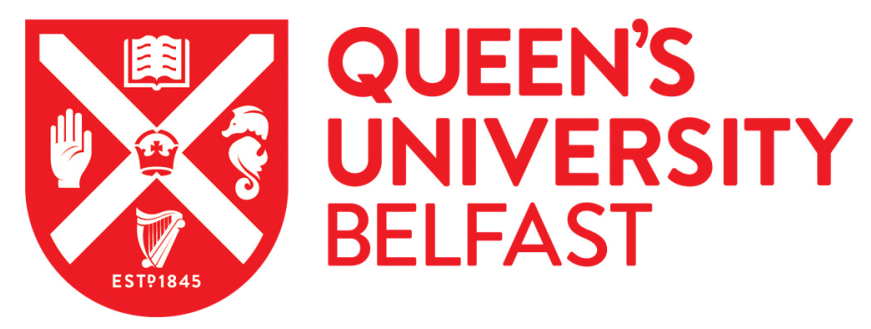

\title{
Sustained participation in community-based physical activity by adolescents with cerebral palsy: a qualitative study
}

Morris, A., Imms, C., Kerr, C., \& Adair, B. (2018). Sustained participation in community-based physical activity by adolescents with cerebral palsy: a qualitative study. Disability and Rehabilitation.

https://doi.org/10.1080/09638288.2018.1486466

Published in:

Disability and Rehabilitation

Document Version:

Peer reviewed version

Queen's University Belfast - Research Portal:

Link to publication record in Queen's University Belfast Research Portal

Publisher rights

( 2018 Taylor and Francis. This work is made available online in accordance with the publisher's policies. Please refer to any applicable terms of use of the publisher.

\section{General rights}

Copyright for the publications made accessible via the Queen's University Belfast Research Portal is retained by the author(s) and / or other copyright owners and it is a condition of accessing these publications that users recognise and abide by the legal requirements associated with these rights.

Take down policy

The Research Portal is Queen's institutional repository that provides access to Queen's research output. Every effort has been made to ensure that content in the Research Portal does not infringe any person's rights, or applicable UK laws. If you discover content in the Research Portal that you believe breaches copyright or violates any law, please contact openaccess@qub.ac.uk. 


\title{
Title: Sustained participation in community-based physical activity by adolescents with cerebral palsy: a qualitative study
}

Running head: Sustained physical activity by adolescents with CP

Article category: Research Paper

\begin{abstract}
Purpose: Short-term physical activity programs may encourage adolescents with cerebral palsy to participate in physical activity but how to sustain their involvement is not well known. This qualitative study aimed to identify facilitators that successfully sustain physical activity participation by adolescents with cerebral palsy.

Materials and methods: Adolescents (12-18 years) with cerebral palsy (Gross Motor Function Classification System (GMFCS) levels I-V, without moderate-severe intellectual disability) who participated in regular physical activity were eligible, as well as one parent and an individual who facilitated their physical activity. Data were gathered using semistructured interviews; verbatim transcripts were analysed using inductive thematic analysis within individuals $(\mathrm{n}=15)$, triads $(\mathrm{n}=5)$, and across participant groups (adolescents, parents and facilitators).
\end{abstract}

Results: Five triads participated (male adolescents, 13-16 years, GMFCS levels I-III). Seven themes emerged: getting started, wanting to succeed, a sense of belonging, the coach is important, endorsement to continue, endorsement to support and being passionate. The themes were synthesised into the Framework for Sustained Participation, which describes the interaction among themes. 
Conclusions: The Framework for Sustained Participation highlights strategies that may be useful for adolescents, parents, sports facilitators, clinicians and researchers to help ambulatory male adolescents with cerebral palsy continue to participate in physical activity.

Keywords: cerebral palsy, physical activity, adolescents, sustained participation, qualitative research

Word count: 5446 


\section{Introduction}

Regular engagement in physical activity is important for maintaining the health of all people; it can improve both physical and mental wellbeing and has been shown to promote muscle strength, cardiovascular endurance, and to lower blood pressure $[1,2,3]$. Regular and sustained physical activity can decrease the probability of developing conditions such as cardiovascular disease, hypertension, and obesity, and may also reduce fatigue, stress, anxiety, depression, and pain [1, 2, 3]. We define sustained physical activity as that conducted at least once per week and maintained for at least 12 months or two sporting or activity seasons. Sustaining physical activity is distinct to 'habitual physical activity', which is any activity involving bodily movement during usual activities of daily living (including sleep, work, leisure) [4]. Infrequent involvement in physical activity may not have the same health benefits as sustained participation; therefore it is important to promote engagement in sustained physical activity practices [5].

Many adolescents with cerebral palsy do not participate in sufficient or regular physical activity [6]. Recommendations exist regarding time spent engaged in physical activity: for example, Australian adolescents are advised to participate in at least 60 minutes of moderate intensity physical activity daily or nearly every day, including play, sports and physical education [1]. While approximately $67 \%$ of typically developing children meet national physical activity guidelines [7], the number of children with a disability engaged in regular physical activity is significantly lower $[6,7,8]$. Verschuren et al [6] reported that less than $18 \%$ of people with cerebral palsy with minimal physical impairment were involved in light physical activity on a regular basis, and only $2-7 \%$ in moderate to vigorous activity. Patterns of physical activity established during childhood and adolescence may be continued through adulthood [3], but participation in physical activity often declines in adolescence $[8,9]$. Consequently, healthy physical activity habits should be established in childhood and continued through adolescence to achieve optimal physical and mental health in adulthood [10]. 
Facilitators and barriers to participation in physical activity by children and adolescents with cerebral palsy have been reported $[11,12,13]$ and categorised as personal (the adolescent), social (their parents/family/other people), environmental (facilities, attitudes), and policy aspects (access and accommodation) $[11,12,14,15,16,17,18,19,20]$, but often only the perspectives of the adolescents and their parents have been reported [12]. The extent to which these factors contribute to sustained participation in physical activity is not well understood. Consequently, this study aimed to identify what factors contribute to sustained participation in physical activity by adolescents with cerebral palsy from the perspectives of the adolescents, their parents, and their community activity facilitator.

\section{Materials and methods}

\section{Study design}

This qualitative study sought to explore the lived experiences of adolescents with cerebral palsy who had successfully sustained their participation in physical activity. Ethical approval was granted from the XXXX (HREC No. XXXX). Informed, written consent was gained from all participants and informed assent from adolescent participants who were less than 18 years old.

\section{Participants}

Participants were recruited as triads, consisting of the adolescent with cerebral palsy, one parent and a key community facilitator of the physical activity (as identified by the adolescent and parent), such as the adolescent's soccer coach, a trainer or their activity coordinator. Triads were sought to gain three different perspectives, as parents and facilitators may identify different factors to those identified by adolescents.

Purposive sampling was used to identify adolescents with cerebral palsy, aged 12-18 years and Gross Motor Function Classification System (GMFCS) [21] levels I-V, who self-identified as participating in regular, sustained physical activity. This age group was chosen due to the known decline in physical activity in adolescents $[8,9]$. Younger children were excluded as full engagement in semi-structured 
interviews may have been challenging for them and may not have yielded sufficient rich data.

Adolescents with moderate to severe intellectual disability (identified by their parents) were excluded from the study, because different facilitators may be important in this group, compared to those important to individuals with a primary physical disability. Adolescents who were unable to communicate using primarily verbal means were also excluded as the study was based on data collected through interviews.

Recruitment occurred through advertisements with local private physiotherapists and community organisations (such as the Cerebral Palsy Support Network), website notices and email notifications. Participant contact details were either forwarded to the research team by the adolescent's local therapist (with the adolescent/family's permission) or participants expressed their interest by contacting the researchers directly.

\section{Procedure}

Demographic characteristics were collected using separate study-specific questionnaires for each participant group. Questionnaires for the adolescents sought information about the adolescent's age, gender, the frequency of activity participation and the length of time that they had been participating in physical activity. Questionnaires for the parents gathered socio-economic information, and information about their adolescent's cerebral palsy. Questionnaires for the facilitators asked about the facilitator's qualifications and their role in the adolescent's physical activity.

Individual semi-structured interviews were conducted using topic guides designed for each participant group to ensure appropriate and distinct information was obtained from each member of the triad. Interview guides were developed based on the findings of a systematic review [11], and focused on what helped the adolescent with cerebral palsy to sustain their participation in physical activity. Interviews with parents gathered information about how the adolescent started in the activity, and what helped them to continue their participation. The interviews with facilitators focused on the influence of their role, and the activity environment, such as the sports club. 


\section{Data analysis}

All interviews were audio recorded and transcribed verbatim. Inductive thematic analysis was used to identify and analyse patterns in the data according to the steps described by Braun and Clarke [22]. All study researchers read interview transcripts. Pertinent sections in the transcripts were identified, coded and discussed between the researchers until consensus was reached. Codes, and the resultant sub-themes and themes, were compared back to original transcripts at each stage of the analysis process. Data were analysed for common sub-themes and themes within individuals $(\mathrm{n}=15)$, within the triads $(\mathrm{n}=5)$, and across participant groups (adolescents, parents and facilitators). Following the primary analysis, the resultant sub-themes, themes and associated meaning statements were further synthesised to illustrate potential relationships between the themes.

\section{Trustworthiness}

Individual interview summaries were sent to participants, who were asked to confirm the researcher's understanding of what was discussed [23]. Four researchers (study authors), two occupational therapists and two physiotherapists, read the transcripts and were involved in the coding process to support the confirmability of results. Discussion of data coding between researchers provided researcher triangulation thereby enhancing the trustworthiness of the results [23]. Trustworthiness and confirmability were also addressed through clear documentation of the audit trail and constant comparison between the codes and the original transcripts.

\section{Results}

Seven adolescents with cerebral palsy who met the selection criteria were identified. Following discussion with the parents of the identified adolescents, five parents and their adolescents (all male; median age 15 years, range 13-16 years; GMFCS levels I-III) agreed to participate in the study. One adolescent did not participate as he was too busy and the other lacked interest in the study. Participants were interviewed in their home, school, physical activity location or local public library. One facilitator was interviewed by 
telephone. Interviews lasted between 16 and 50 minutes: adolescent interviews were typically of shorter duration than parent and facilitator interviews. Tables 1-3 summarise the demographic characteristics of each participant group. Fourteen participants lived in or near a large metropolitan city, while one lived in a metropolitan fringe district, and the socioeconomic status for the majority of the parents was relatively high (Table 2). Participants were assigned individual study codes describing their participant group (Adolescent, A; Parent, P; Facilitator, F) and their triad (1-5); for example, A4, is an adolescent from triad 4. These codes are used within the reporting of results.

$<$ Insert Tables 1-3 near here $>$

Seven themes were identified through the inductive thematic analysis of the interview data: i) getting started, ii) wanting to succeed, iii) a sense of belonging, iv) the coach is important, v) endorsement to continue, vi) endorsement to support, and vii) being passionate. Table 4 provides an overview of the 23 sub-themes, seven themes and associated meaning statements.

\section{$<$ Insert Table 4 here $>$}

\section{Theme 1: Getting started}

Successful sustained participation was described in the context of strong, positive initial experiences with the activity. All participants discussed the importance of factors related to getting started in the activity, with subthemes focused on choosing the right activity, getting the right fit, and greasing the chute.

All of the adolescent participants discussed choosing the right activity, that was, an activity that they were interested in and one that matched their capacity: One adolescent stated, "Well I know I can't play football, it's a bit too hard" [A4]. Another adolescent was interested in swimming, "I started doing swimming lessons just because I went to the beach a lot and I just wanted to learn how to swim" [A2]. Parents also discussed matching the activity to the adolescent's capacity: "if he's playing like with like, he can then excel in that particular sport" [P4]. 
Getting the right fit of the activity for all involved (adolescents, parents, and facilitators) was important. Several adolescents, parents and facilitators thought that the activity needed to be tailored to the adolescent to provide them with an achievable challenge. One adolescent said "because I've got a personal trainer the program's tailored to me and... I don't have to try and keep up with other people my age" [A1]. His mother reinforced the importance of tailoring the activity, stating: "certainly the way that the program is personalised means that it's within his ability ... specific tailoring means that he is not over-extending himself and then therefore becoming either bored or put off' [P1]. Conversely, another parent commented on her belief that her adolescent's activity of choice was not the right fit due to the physical challenges associated with participation in a mixed-aged sports club: "I was very frustrated and very disappointed and I did not want him to continue at all because of the age difference. For [the adolescent] to actually manoeuvre around the court, he was struggling because of the muscle tone in his upper body and trying to manoeuvre his chair and watch the ball that was going so fast. I actually hated it and I didn't want him to go ahead. I hated it" [P4]. In spite of this parent's reservations, she continued to facilitate her son's attendance.

Another sub-theme of getting the right fit was it fits with our schedule. This was discussed by all participants from Triad 1 - the adolescent continued with his chosen activity as he could do it quickly: "you can get it (a gym program) done in much quicker time than say if you went for a run or something like that" [A1].

Four of the five parents indicated the importance of greasing the chute, that is, doing background or preparatory work to assist the adolescent to have an optimal start: "(I had to) do a lot of work initially getting them to understand his needs" [P2]. One facilitator noted that their background knowledge of facilities helped the adolescents to participate: "knowing who the refs [referees] are... they've got wheelchairs that we can use. We know this stadium, that they've got the facilities, you know, wheelchair accessible, that sort of stuff" [F4]. 


\section{Theme 2: Wanting to succeed}

Sub-themes associated with wanting to succeed included challenges and achievement, hoping to become big and being determined. Once the adolescent had become involved in their activity, wanting to succeed helped many to continue their participation. Some parents and facilitators thought that the adolescents experiencing challenges and achievement encouraged their participation, for instance, one parent commented: "He actually enjoys the training because it's quite challenging as well, they really push them and sometimes he'll come out exhausted, but he'll say... 'I swam three kilometres today'... That's challenging and achievement as well." [P2]. Another commented on the importance of the adolescent earning their achievement: "Nobody has given it to him and to me, that's I suppose the biggest thing, that no-one has just given it to him, he's done that himself. He's earned that" [P4].

Hoping to become big was identified as an important sub-theme by three of the five triads. One adolescent's goal was to represent his country in the Paralympics: he stated, "I'm hoping to become big. It started off as a hobby, and then it got bigger and bigger every year" [A3]. One parent noted that a sense of achievement gave her adolescent the drive to continue: "all of a sudden he found that he was achieving things and he went to State [competitions], he went to Nationals, won medals, so that really gave him the drive to compete, because he'd come home and everyone at school knew him because he was the one that came home with the most medals" [P2].

The adolescents' determination to participate was discussed across all participant groups (being determined): "Probably proving to people that my ability is greater than my disability. To show people that I could actually run, even if I did have a dodgy leg" [A5]. His mother noted that "[the adolescent] is very, very determined and he has a desire to be good at things" [P5].

\section{Theme 3: A sense of belonging}

The sub-themes associated with a sense of belonging included doing the same thing as everyone else, 
being part of the club, and the family belongs too. Building a sense of belonging whilst involved in the activity encouraged some of the adolescents to continue their participation. Triad 1 described the importance of the adolescent doing the same thing as everyone else: "I do it to sort of feel as if it's a normality sort of thing. I do it to feel like all the people around me there, normal people and they're doing their workout sort of thing and I'm in the same sort of, I guess, zone as them, the same sort of community as them I guess" [A1]. His mother noted that "it's also in an environment that he gets to see other people doing, regular-bodied people, doing the same thing as he is" [P1]. The facilitator of this adolescent's activity believed that treating him like anyone else was important to him continuing to go to the gym: "the way I talk to him is the way I talk to any of my clients... that's probably a key point of engagement... I don't talk down to him... I just treat him like I treat anybody else" [F1].

Adolescents and parents suggested they built a sense of belonging from being part of the club and having something in common with others. One facilitator thought that the adolescents developing friendships through the activity was important: "friendships are probably the biggest thing that I would say that the kids get from this program" [F2]. Interestingly, only one adolescent discussed making friends through engagement in their physical activity, noting, "I got to meet people who were exactly like me" [A3], a sentiment that was reiterated by his mother who liked that her son was "playing with kids that are similar to himself" [P3]. In triad 5, both the adolescent and his mother noted the importance of the social aspect of his participation in the activity: "the social part was so important to him" [P5]. Two of the parents spoke about feeling a sense of belonging through their adolescent's participation in the activity (family belongs too): "I'll try and go along, because I do enjoy the networking with the other families" [P3].

\section{Theme 4: The "coach" is important}

The sub-themes associated with the coach is important were: getting the right coach, coaching style and more than a personal trainer. Many of the participants discussed the importance of getting the right coach or facilitator of the activity, for example, "If you don't like the personal trainer then you're going to 
think 'do I really want to keep doing this sort of thing?"” [A1]. The facilitator also thought that having the right trainer was important to both the adolescent and the parent, as they changed their schedule to fit in with the facilitator's schedule. "Instead of thinking about someone else, they changed their schedule to accommodate my work schedule" [F1].

Most of the facilitators discussed the positive impact of their coaching style, which included their attitude, going beyond the facilitating role and doing further research. One commented on the importance of the coach's attitude, "that's our ethos. To do what you can do to help people achieve their goals and to do as best they can" [F5]. She also discussed going beyond the facilitating role "it's your own on-going development and knowledge and making the opportunity to learn as much as you can about what's the best way to assist someone with whatever disability" [F5]. One parent spoke of the facilitator doing an extra course that helped the adolescent: "So he's really, really keen, enjoying heaps of research and has helped [the adolescent]. You can tell it makes [him] feel like he's important and he can actually achieve something so I think that's been really good for him" [P2].

The importance of having a meaningful relationship between the facilitator and adolescent, with the facilitator being more than a personal trainer was particularly evident with triad 1 . The adolescent thought that he had "a good relationship" [A1] with his facilitator and thought of the facilitator as "more than a personal trainer" [A1]. The parent discussed the importance of the relationship: "the personality and bonding needs to be a fit with the child because it's hard enough let alone if the trainer doesn't create that bond" [P1]. The facilitator also noted the importance of the relationship she had with the adolescent: "Just having the rapport with him. Having built that up over time" [F1].

\section{Theme 5: Endorsement to continue}

The sub-themes related to this theme included I feel better if I'm fit and healthy [A1], the club helps me participate and other people want me to succeed. Participants identified a range of personal and external factors that encouraged sustained participation. Adolescent participants discussed feeling better if they 
were fit and healthy, including one adolescent noticing that not going to the gym affected his legs: "I definitely walk better when I've been to the gym and since I've been coming to the gym" [A1]. Parents commented on physical activity being good for the adolescents, for example: "the physical activity's good for [the adolescent]. Obviously, the more he moves around, the better it is for him. His muscles can get stiff and things like that, so physical activity keeps his body going" [P3]. Parents also noticed the mental health benefits of the activity, "[It's] really important for him to keep doing sport because it really lifts him up" [P2]. One facilitator emphasised how the activity helped with the adolescent's daily functioning: "For [the adolescent], the benefits are daily functioning and balance and walking around and keeping up with his friends" [F1].

All facilitators, and some adolescents and parents, noted that the sports club or activity organisation was another important aspect (the club helps me participate). One adolescent talked about the facility staff being nice: "they're all nice. They all help" [A2]. His parent discussed the supportive atmosphere: "I think if the swim club weren't as supportive, kids might not be as supportive. I think it's just a really good atmosphere" [P2]. Facilitators also commented on the helpfulness and accommodations made by the facilities with regard to providing services at cost price and making modifications to permit wheelchair access.

All participant groups discussed that other people want me [the adolescent] to succeed. Adolescents talked about their family and coach wanting them to succeed, and the encouragement of friends. One discussed wanting to meet the expectations of his coach and family: "yeah, my coach and my family... keep on telling me to keep swimming and my coach expects me to do a certain amount of sessions a week" [A2]. Parents commented on the support of professionals, such as physiotherapists: "Every time she [the physiotherapist] saw [the adolescent] you know, how's your running going? How's your sport? Very encouraging" [P2]. One parent felt that the adolescent appreciated the support of others for his chosen activity, "I think [the adolescent] knows that the people he's involved with are all on the same 
page, all believe it's the right, appropriate exercise" [P1]. One facilitator thought that it was the family's support that helped the adolescent to succeed: "I think one of the reasons he's kept going and was quite successful, and still is, is because of his family. They understood that to get anywhere, you have to practice and you have to understand what you're doing, but they were also supportive of that" [F5].

\section{Theme 6: Endorsement to support}

Parents and facilitators discussed factors that encourage those involved with the adolescent to continue to support the adolescent's participation; these included the coach's reward, the benefits to the club, and the family celebrating their child's success. Facilitators felt they were also being rewarded (coach's reward) by helping the adolescents with something important and seeing them succeed, for example, "Knowing that I'm helping someone with such an important part of his life, that will hopefully set him up in the future" [F1]. Facilitators discussed the benefits that the adolescent's involvement brought to the facility, such as recognition as being an inclusive facility within the community: "You want to be able to use those aspects [supporting people with disability to participate] when you're pitching your club to get funding from the government or whatever - facility upgrades or stuff like that" [F3].

Parents mentioned that the family enjoyed celebrating the adolescent's success: "we all went up to watch the grand final... My husband had never been before so that was really good. We all loved going and watching and cheering and everything like that" [P4].

\section{Theme 7: Being passionate}

Nearly all participants discussed being passionate about sport or the particular activity. The sub-themes associated with this theme included: sport is my passion, enjoying the activity and our family loves sport. Three adolescents discussed their passion for sport being a drive for them to find a way to participate (sport is my passion): “I like watching sport a lot. It's one of my passions but I can't obviously do it as much as other people do but I do it as much as I can. If there's a way that I can participate in something I 
always do, scoring or umpiring, whatever" [A1]. Parents also commented on the adolescent's love of sport: “[he's] a real sports tragic" [P1].

All of the adolescent participants mentioned enjoying the particular activity that they were involved in, as opposed to having a general passion for sport, (enjoying the activity). This enjoyment of a particular activity was emphasised by one adolescent: "It's [soccer] just my passion" and that not being able to participate in soccer "would kill me" [A3].

Several parent participants reported that their family members generally valued participation in sport (our family loves sport). Parents spoke of promoting and valuing physical activity: "we actively promote sport in our family" [P5]. One facilitator noted that having a sporting family helped the adolescent to continue participating in the activity: "his family were a sporting family and they understood what was involved in sport, so they were prepared to take him to training and take him to things" [F5].

\section{Synthesis of findings}

A variety of factors that helped the adolescents to get started and then crucially, to continue participating in their selected activity were identified in this study. Following a period of supported commencement of the activity (getting started), adolescents needed to be motivated by wanting to succeed, or building $a$ sense of belonging, which facilitated their sustained participation. The coach is important, endorsement to continue and endorsement to support helped motivate the adolescents to participate. Being passionate about physical activity was important through all stages of participation: it facilitated adolescents to get started and then sustained their involvement in the activity, supporting the continuation of participation in physical activity over time. The Framework for Sustained Participation (Figure 1), illustrates how the seven derived themes are hypothesised to interact to support sustained participation for the participants in this study. 


\section{Discussion}

The Framework for Sustained Participation was derived from the factors identified by parents, facilitators and adolescents with cerebral palsy who have successfully sustained participation in physical activity and may be of value to adolescents and parents, healthcare professionals, sporting clubs, agencies and facilities, when planning how best to enable sustained physical activity participation by young people with cerebral palsy.

The findings of the current study are consistent with previous literature, which identified that enjoyment, believing that physical activity is important, preferences, and having a sense of belonging, are facilitators for physical activity by children and adolescents with cerebral palsy [12, 24, 25]. Similarly, this study confirmed that adolescents participate in physical activity when the activity type is based on their preference, when it is matched to their capacity, and when it provides a challenge [24]. These findings are consistent with self-determination theory that highlights the importance of relatedness, competence and autonomy to meeting participation goals [26]. The findings of this study are also consistent with the Health Action Process Approach (HAPA) principles that motivation and volition are required to change health behaviour [27]. In contrast to Shimmell et al [12] however, one of the motivators for some adolescents to commence and continue to participate in physical activity in the current study were the perceived health benefits.

The findings from this study provide some challenge to the existing literature on the importance of friendship as a motivator for sustained participation in physical activities. Previous studies identified friendship as a facilitator of physical activity $[12,24]$, and the absence of friends as a barrier to participation in physical activities [24]. Only one of the adolescent participants in the current study discussed friendship as an important contributor to his on-going participation, whereas other adolescents related more to $a$ sense of belonging within their local community or were motivated by feeling better if they were fit and healthy. This suggests that clinicians, health professionals and other individuals who 
promote participation in physical activity should ensure that the environment is inclusive and provides the adolescent with a sense of belonging. This may relate to the development of specific friendships, but may not be dependent on friends taking part alongside the adolescent at the outset. The education provided to the adolescents about the underlying health reasons for participating in physical activity may also be an important consideration for parents, healthcare providers and activity facilitators.

The impact of contextual factors, such as financial resources, was not evident in the results of this study. Unlike previous studies [11, 12], participants in this study did not discuss finances as a major facilitator or barrier to the participation of adolescents in physical activity, despite the inclusion of families of diverse resources. Given that participants were recruited on the basis of being involved in regular physical activity, cost may not have been a factor, or had already been addressed if problematic. However, this finding may have differed if we had focused on barriers to sustained physical activity, and recruited participants from more diverse socio-economic backgrounds and educational attainment levels. The introduction of a new approach to allocation of funding for disability services in Australia (the National Disability Insurance Scheme) has resulted in individuals having more control and choice over the services they receive. This has the potential to lead to increased community participation [28] and thus may afford further opportunities for sustaining involvement in physical activity over time.

Any potential impact of gender cannot be ascertained from this study due to our inability to recruit female adolescent participants; consequently further research is needed to understand whether the results of this study may be transferable to female adolescents with cerebral palsy. Although gender has previously been found to impact participation in physical activity in non-disabled adolescents $[29,30]$, a systematic review [31] and population-based study from Sweden [32] found that gender was not correlated with physical activity in children with physical disabilities. It is possible, however, that female adolescents may require tailored interventions to get them started, and sustain participation in physical activity [33].

Although preferences are not synonymous with participation, the family of Participation-Related 
Constructs (fPRC) framework $[34,35]$ recognises the effect that a child's preferences (interests and passions) can have on their participation. The themes identified in the current study were consistent with the constructs described in the fPRC. According to the fPRC framework, activity competence, sense of self and preferences can influence current and future participation of children with disabilities, as well as be influenced by their past participation [34]. Adolescents choosing to participate in a preferred activity may result in continued attendance and involvement in the activity [34]. Participants in the current study discussed the sense of achievement they felt when participating in their chosen activity, which may have contributed to building their competence and a positive sense of self. Exercising choice, and enjoying their chosen activity, helped participants in this study to get started in the activity and continue their participation. Parent participants described the physical activity giving the adolescents confidence and self-esteem, elements of the construct of sense of self within the fPRC. To improve or achieve a certain level of competence the activity needs to be the right fit, or tailored to the adolescent, so as to provide an achievable challenge, thus addressing contextual elements of participation. This is consistent with prior systematic review findings that individually tailored programs may be more effective than standardised programs at improving participation for children with disabilities [36].

\section{Strengths and limitations}

The current study explicitly focused on the facilitators, rather than barriers, of sustained physical activity participation. Addressing potential barriers to participation, in addition to implementing facilitating strategies, is also likely to be important. As this study employed purposive sampling, we sought adolescents who were engaged and motivated to participate in physical activity. It is possible that motivators and facilitators may be different for adolescents and parents who are not already engaged in physical activity, but this participant group were not investigated as part of the current study. It was not possible to determine the number of potentially eligible participants: despite numerous efforts to recruit using purposive sampling through private physiotherapists, only seven potential adolescent participants were identified. Despite attempts to recruit female adolescents and participants from a range of socio- 
economic and geographic locations, the final participant group means the results of this study are only transferable to male adolescents with cerebral palsy. The relatively small number of included triads may also impact on transferability of findings. Inclusion of three participant groups and consistency of themes across participants was evident. It is possible that further recruitment and data collection would uncover additional facilitators of sustained participation, however the present study employed robust methods to ensure rigor in the process and product of research [37], reliability in the data analysis [38] and trustworthiness in the interpretation of results [39]. Contributing to these methods, a decision trail was kept throughout the study to promote clarity about how the study was completed, and to confirm the results. Member checking through sharing interview summaries with participants was used to develop credibility.

\section{Conclusions}

The Framework for Sustained Participation, derived from the perspectives of adolescents, parents and facilitators, is consistent with self-determination theory, HAPA principles and the fPRC. The framework may be used to guide parents, clinicians and activity facilitators in supporting adolescents to sustain participation in their chosen physical activity by providing practical examples of strategies that have been useful for others. The current study indicates that adolescents need to enjoy and exercise choice about the type of activity to enable getting started in, and sustaining, regular physical activity. Clinicians and facilitators can support adolescents in their participation by assisting adolescents to find an activity that fits with their capacity and is individually tailored to the circumstances of the adolescent to promote competence. Getting the right coach or facilitator to work with the adolescent within an inclusive environment with support from others will likely assist the adolescent in sustaining their participation in the context in which it occurs. Future research is required to test the hypothesised relationships described in the Framework for Sustained Participation and its applicability to other populations, including adolescents who need to become more physically active, females with cerebral palsy and young people with other physical disabilities and from other socio-cultural backgrounds. 
Sustained physical activity by adolescents with CP

\section{Acknowledgments}

The authors wish to thank the adolescents, parents and facilitators who participated in the study, and the organisations and private physiotherapists who assisted with recruitment. 


\section{References}

1. Australian Government - Department of Health. Australia's Physical Activity \& Sedentary Behaviour Guidelines for Young People (13 -17 years). 2014.

2. Owen N, Spathonis K, Leslie E. Physical activity and health. In: Ayers S, Baum A, McManus C, editors. Cambridge Handbook of Psychology, Health and Medicine: Cambridge University Press; 2007.

3. Trost S. Discussion paper for the development of recommendations for children's and youths' participation in health promoting physical activity. Queensland, Australia: Australian Government, Department of Health and Ageing; 2005.

4. Shkedy Rabani A, Harries N, Namoora I, et al. Duration and patterns of habitual physical activity in adolescents and young adults with cerebral palsy. Dev Med Child Neurol. 2014;56(7):673-680. doi: 10.1111/dmen.12394.

5. Janssen I, LeBlanc AG. Systematic review of the health benefits of physical activity and fitness in school-aged children and youth. International Journal of Behavioral Nutrition and Physical Activity. 2010;7. doi: 10.1186/1479-5868-7-40.

6. Verschuren O, Peterson MD, Balemans ACJ, et al. Exercise and physical activity recommendations for people with cerebral palsy. Dev Med Child Neurol. 2016. doi: 10.1111/dmen.13053.

7. Dobbins M, DeCorby K, Robeson P, et al. School-based physical activity programs for promoting physical activity and fitness in children and adolescents aged 6-18. Cochrane Database of Systematic Reviews. 2009 (1). doi: 10.1002/14651858.CD007651. 
8. Dumith SC, Gigante DP, Domingues MR, et al. Physical activity change during adolescence: a systematic review and a pooled analysis. International Journal of Epidemiology. 2011;40(3):685698. doi: 10.1093/ije/dyq272.

9. Imms C, Adair B. Participation trajectories: impact of school transitions on children and adolescents with cerebral palsy. Dev Med Child Neurol. 2017;59(2):174-182. doi: 10.1111/dmen.13229.

10. Koldoff EA, Holtzclaw BJ. Physical Activity Among Adolescents with Cerebral Palsy: An Integrative Review. J Pediatr Nurs. 2015;30(5):e105-e117. doi: 10.1016/j.pedn.2015.05.027.

11. Shields N, Synnot AJ, Barr M. Perceived barriers and facilitators to physical activity for children with disability: a systematic review. Br J Sports Med. 2012;46(14):989. doi: 10.1136/bjsports2011-090236.

12. Shimmell LJ, Gorter JW, Jackson D, et al. "It's the participation that motivates him": physical activity experiences of youth with cerebral palsy and their parents. Phys Occup Ther Pediatr. 2013;33(4):405-420. doi: 10.3109/01942638.2013.791916. PubMed PMID: 23663137.

13. Schreiner B. Being young with cerebral palsy, experiences of, and thoughts about physical activity and participation - a qualitative focus group study. Physiotherapy. 2015;101(Supplement 1):e1352. doi: 10.1016/j.physio.2015.03.1286.

14. Mitchell LE, Ziviani J, Boyd RN. Characteristics associated with physical activity among independently ambulant children and adolescents with unilateral cerebral palsy. Dev Med Child Neurol. 2015;57(2):167-174. doi: 10.1111/dmcn.12560.

15. Conchar L, Bantjes J, Swartz L, et al. Barriers and facilitators to participation in physical activity: The experiences of a group of South African adolescents with cerebral palsy. J Health Psychol. 2016;21(2):152-163. doi: 10.1177/1359105314523305. 
16. Wright A, Roberts R, Bowman G, et al. Barriers and facilitators to physical activity participation for children with physical disability: comparing and contrasting the views of children, young people, and their clinicians. Disabil Rehabil. 2018:1-9. doi: 10.1080/09638288.2018.1432702.

17. Jaarsma EA, Dijkstra PU, De Blécourt ACE, et al. Barriers and facilitators of sports in children with physical disabilities: A mixed-method study. Disabil Rehabil. 2015;37(18):1617-1625. doi: $10.3109 / 09638288.2014 .972587$.

18. Buffart LM, Westendorp T, Van Den Berg-Emons RJ, et al. Perceived barriers to and facilitators of physical activity in young adults with childhood-onset physical disabilities. J Rehabil Med. 2009;41(11):881-885. doi: 10.2340/16501977-0420.

19. Vogts N, MacKey AH, Ameratunga S, et al. Parent-perceived barriers to participation in children and adolescents with cerebral palsy. J Paediatr Child Health. 2010;46(11):680-685. doi: 10.1111/j.1440-1754.2010.01815.x.

20. Lauruschkus K, Nordmark E, Hallström I. Parents' experiences of participation in physical activities for children with cerebral palsy-protecting and pushing towards independence. Disabil Rehabil. 2017;39(8):771-778. doi: 10.3109/09638288.2016.1161841.

21. Palisano R, Rosenbaum P, Walter S, et al. Development and reliability of a system to classify gross motor function in children with cerebral palsy. Dev Med Child Neurol. 1997;39(4):214223.

22. Braun V, Clarke V. Using thematic analysis in psychology. Qualitative Research in Psychology. 2006;3(2):77-101. doi: 10.1191/1478088706qp063oa.

23. Portney LG, Watkins MP. Foundations of clinical research : applications to practice. 3rd Edition. ed. Phiiladelphia, PA: F.A. Davis Company; 2015. 
24. Lauruschkus K, Nordmark E, Hallström I. 'It's fun, but ...' Children with cerebral palsy and their experiences of participation in physical activities. Disabil Rehabil. 2015;37(4):283-289. PubMed PMID: 100749484.

25. Verschuren O, Wiart L, Hermans D, et al. Identification of Facilitators and Barriers to Physical Activity in Children and Adolescents with Cerebral Palsy. The Journal of Pediatrics. 2012 9//;161(3):488-494. doi: http://dx.doi.org/10.1016/j.jpeds.2012.02.042.

26. Poulsen AA, Ziviani J, Cuskelly M, editors. Goal setting and motivation in therapy: Engaging children and parents. London, UK: Jessica Kingsley Publishers; 2015.

27. Schwarzer R. Modeling health behavior change: How to predict and modify the adoption and maintenance of health behaviors. Applied Psychology. 2008;57(1):1-29. doi: 10.1111/j.14640597.2007.00325.x.

28. Reddihough DS, Meehan E, Stott NS, et al. The National Disability Insurance Scheme: a time for real change in Australia. Dev Med Child Neurol. 2016;58:66-70. doi: 10.1111/dmcn.13007.

29. Vilhjalmsson R, Kristjansdottir G. Gender differences in physical activity in older children and adolescents: The central role of organized sport. Soc Sci Med. 2003;56(2):363-374. doi: $10.1016 / \mathrm{S} 0277-9536(02) 00042-4$.

30. Nader PR, Bradley RH, Houts RM, et al. Moderate-to-vigorous physical activity from ages 9 to 15 years. JAMA - Journal of the American Medical Association. 2008;300(3):295-305. doi: 10.1001/jama.300.3.295.

31. Li R, Sit CHP, Yu JJ, et al. Correlates of physical activity in children and adolescents with physical disabilities: A systematic review. Prev Med. 2016;89:184-193. doi: 10.1016/j.ypmed.2016.05.029. 
32. Lauruschkus K, Westbom L, Hallström I, et al. Physical activity in a total population of children and adolescents with cerebral palsy. Res Dev Disabil. 2013;34(1):157-167. doi: 10.1016/j.ridd.2012.07.005.

33. Jago R, Edwards MJ, Sebire SJ, et al. Bristol girls dance project (BGDP): protocol for a cluster randomised controlled trial of an after-school dance programme to increase physical activity among 11-12 year old girls. BMC Public Health. 2013;13:1003. doi: 10.1186/1471-2458-131003.

34. Imms C, Granlund M, Wilson PH, et al. Participation - both a means and an end: a conceptual analysis of processes and outcomes in childhood disability. Dev Med Child Neurol. 2016. doi: 10.1111/dmen.13237.

35. Imms C, Adair B, Keen D, et al. 'Participation': A systematic review of language, definitions, and constructs used in intervention research with children with disabilities. Dev Med Child Neurol. 2016;58(1):29-38. doi: 10.1111/dmcn.12932.

36. Adair B, Ullenhag A, Keen D, et al. The effect of interventions aimed at improving participation outcomes for children with disabilities: a systematic review. Dev Med Child Neurol. 2015;57(12):1093-1104. doi: 10.1111/dmcn.12809.

37. Golafshani N. Understanding Reliability and Validity in Qualitative Research. The Qualitative Report 2003. Available from: http://nsuworks.nova.edu/tqr/vol8/iss4/6.

38. Mays N, Pope C. Qualitative Research: Rigour and qualitative research [Article]. BMJ. 1995;311(6997):109. doi: 10.1136/bmj.311.6997.109.

39. Thorne S. Interpretive Description. New York, NY: Routledge; 2008. (Developing Qualitative Inquiry). 


\section{Figure captions}

Figure 1. A Framework for Sustained Participation in physical activity by adolescents with cerebral palsy

The overarching downward arrow in this figure represents the continuation of participation in physical activity over time. The light vertical boxes represent the facilitators of sustained participation. The three horizontal boxes in the centre of the image represent the motivators of sustained participation, which provide potential targets for supportive intervention. Being passionate was hypothesised as an important factor throughout the various stages of sustained participation: influencing the desire for an adolescent to get started in an activity and impacting on their ongoing participation. The arrows represent hypothesised relationships among the factors and sustained participation. 
Table 1. Demographic Characteristics of Adolescent Participants

\begin{tabular}{|c|c|c|c|c|c|}
\hline Variable & Triad 1 & Triad 2 & Triad 3 & Triad 4 & Triad 5 \\
\hline Age & $15 \mathrm{y} 9 \mathrm{~m}$ & $13 \mathrm{y} 6 \mathrm{~m}$ & $14 \mathrm{y} 8 \mathrm{~m}$ & $15 \mathrm{y} 4 \mathrm{~m}$ & $16 \mathrm{y} 0 \mathrm{~m}$ \\
\hline School year level & 10 & 8 & 8 & 9 & 10 \\
\hline Number of siblings & 1 & 1 & 1 & 1 & 2 \\
\hline Single/two parent family & Single & Double & Double & Single & Double \\
\hline Main Physical Activity & Gym & Swimming & Soccer & Bike riding & Athletics \\
\hline \multirow[t]{4}{*}{ Other Physical Activity } & Table tennis & Tennis, running, surfing, & Swimming, PE at & Swimming, & Swimming, \\
\hline & & mountain bike riding, surf & school & wheelchair & football, cricket, \\
\hline & & life saving, table tennis, & & basketball, walking, & basketball \\
\hline & & athletics, PE at school & & gym, running & \\
\hline Frequency of main PA & $2 \mathrm{x}$ per week & $4 \mathrm{x}$ per week & 1x per two weeks & $1 \mathrm{x}$ per week & 5-6x per week \\
\hline
\end{tabular}




\begin{tabular}{|c|c|c|c|c|c|}
\hline $\begin{array}{l}\text { Length of time participating } \\
\text { in main PA }\end{array}$ & 5 years & $\begin{array}{l}4 \text { years of competition } \\
\text { swimming, lessons prior to } \\
\text { that }\end{array}$ & 7 years & 2.5 years & 2 years \\
\hline Type of school & Mainstream & Mainstream & Mainstream & Special school & Mainstream \\
\hline $\mathrm{CP}$ distribution & Diplegia & Diplegia & Triplegia & Unknown & Diplegia \\
\hline Movement disorder & Spasticity & Spasticity & Mixed & Mixed & Spasticity \\
\hline GMFCS level & III & I & I & II & I \\
\hline Other medical conditions & None & None & Asthma & $\begin{array}{l}\text { Mild ID, Macular } \\
\text { Dystrophy }\end{array}$ & Asthma \\
\hline Walking aids & $\begin{array}{l}\text { Walking stick for } \\
\text { short distance within } \\
\text { buildings but not at } \\
\text { home, electric scooter }\end{array}$ & None & None & $\begin{array}{l}\text { Crutches } \\
\text { (sometimes), manual } \\
\text { wheelchair } \\
\text { (sometimes) }\end{array}$ & None \\
\hline
\end{tabular}




$\begin{array}{lllll}\text { People present during } & \text { Adolescent and } & \text { Adolescent and } & \text { Adolescent, mother, Adolescent, mother } & \text { Adolescent, mother } \\ \text { interview } & \text { interviewer; mother } & \text { father and } & \text { and interviewer } & \text { and interviewer } \\ & \text { occasionally present but } & \text { interviewer - father } & \\ & \text { did not participate } & \text { participated in } & \\ & & \text { interview }\end{array}$

Note. $\mathrm{y}=$ years; $\mathrm{m}$ = months; $\mathrm{PE}=$ physical education classes; $\mathrm{PA}=$ physical activity; $\mathrm{CP}=$ Cerebral Palsy; GMFCS = Gross Motor Function

Classification System; ID = Intellectual disability. No adolescent participants used alternative or augmentative communication devices. All

adolescent participants were male and all indicated that English was the primary language spoken at home. 
Table 2. Demographic Characteristics of Parent Participants

\begin{tabular}{|c|c|c|c|c|c|}
\hline Variable & Triad 1 & Triad 2 & Triad 3 & Triad 4 & Triad 5 \\
\hline Age bracket (years) & $55-64$ & $45-54$ & $45-54$ & $45-54$ & $35-44$ \\
\hline Highest level of education & Postgraduate & Tertiary education & Tertiary education & Tertiary education & Tertiary education \\
\hline Level of employment & Seeking employment & Part time & Full time & Full time & Full time \\
\hline $\begin{array}{l}\text { Total annual household } \\
\text { income (AUD) }\end{array}$ & $\$ 25,000-\$ 34,999$ & $\$ 200,000+$ & $\$ 150,000-\$ 199,999$ & Not specified & $\$ 100,000-\$ 149,000$ \\
\hline People present during & Parent and & Parent and interviewer & Parent and & Parent and & Parent, adolescent \\
\hline interview & interviewer & & $\begin{array}{l}\text { interviewer, } \\
\text { adolescent } \\
\text { occasionally } \\
\text { present/participated }\end{array}$ & interviewer & and interviewer \\
\hline
\end{tabular}


Table 3. Demographic Characteristics of Facilitator Participants

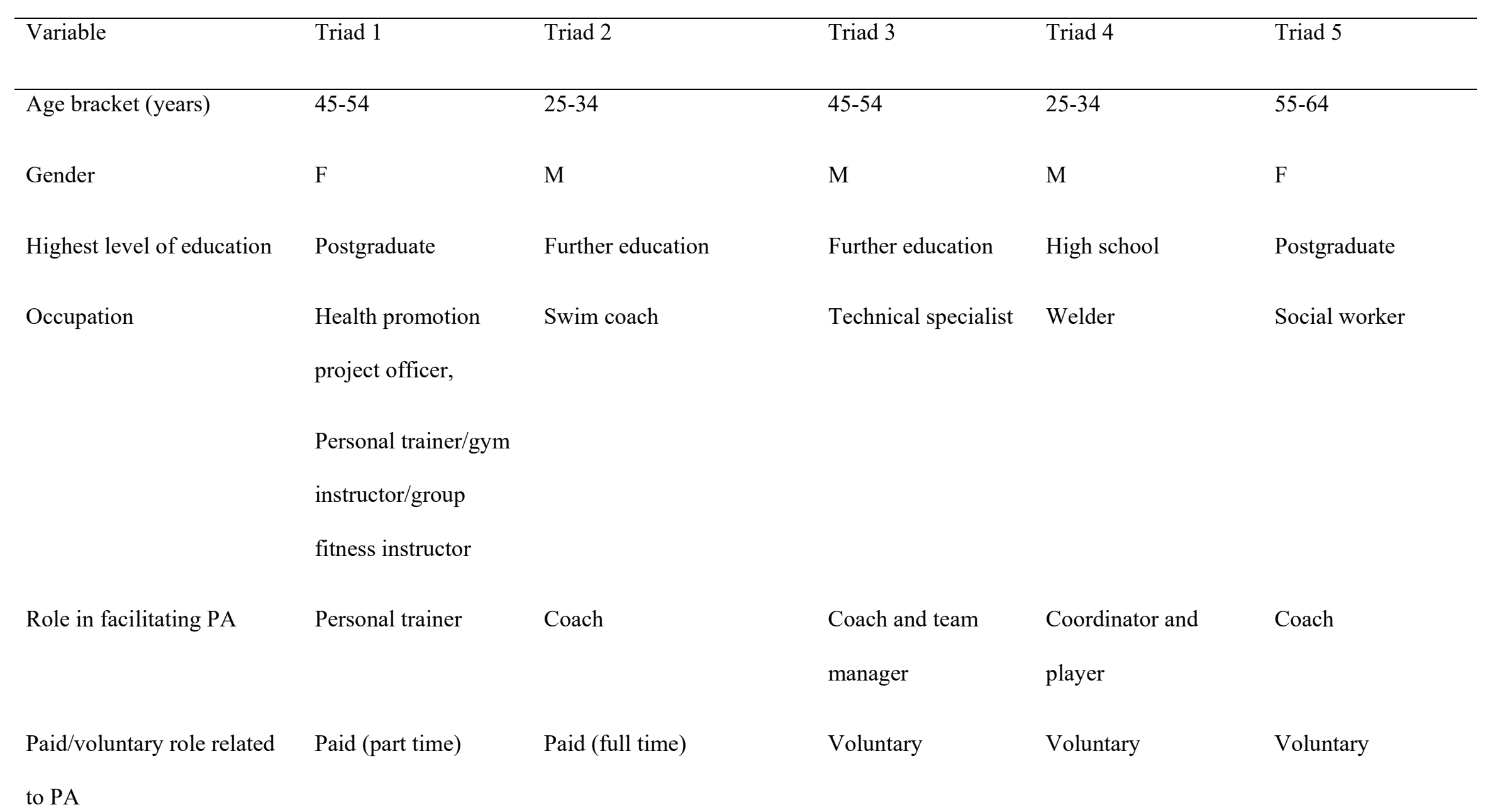




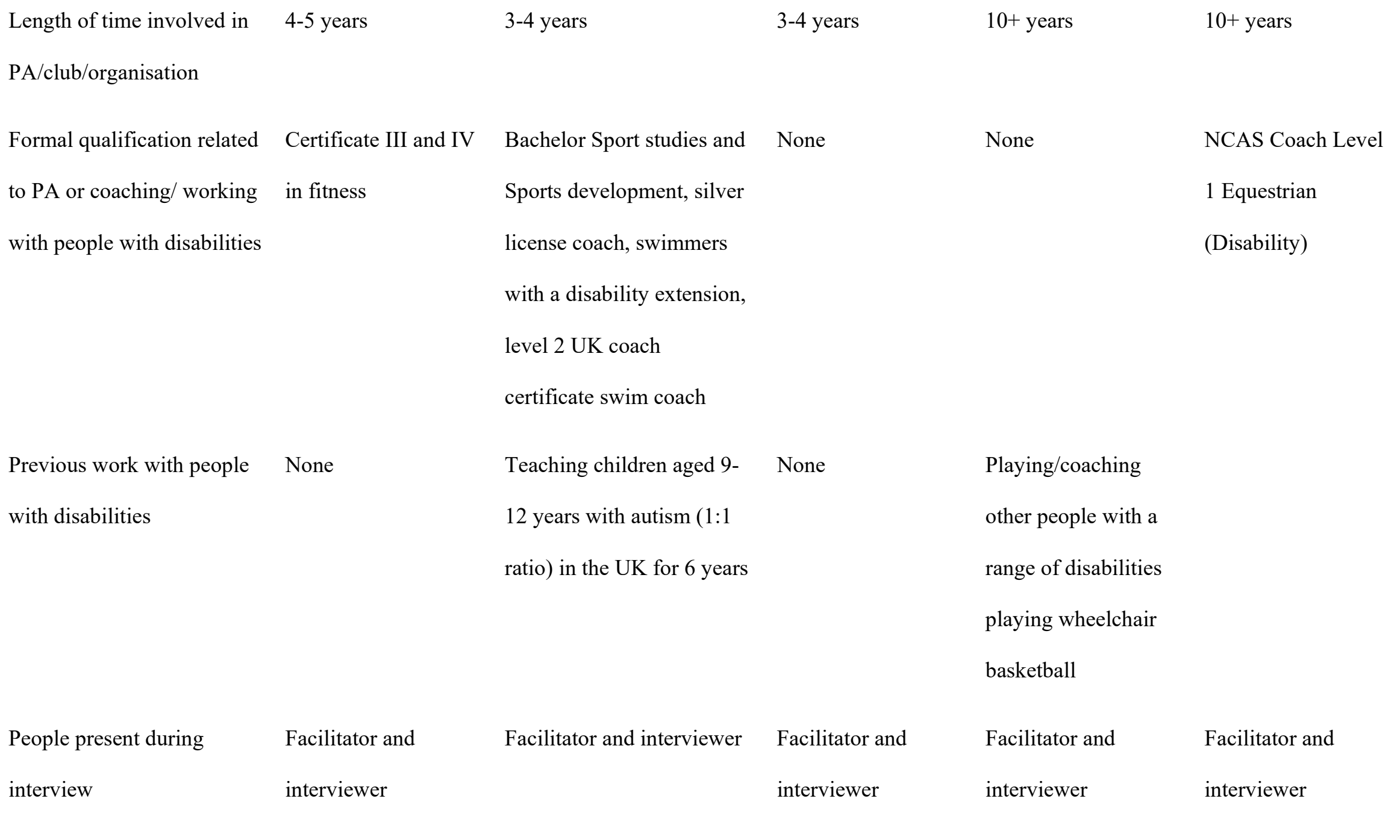

Note. $\mathrm{M}=$ male $; \mathrm{F}$ = female; $\mathrm{PA}=$ physical activity $; \mathrm{UK}=$ United Kingdom; NCAS = National Coaching Accreditation Scheme. 
Table 4. Themes and Meaning Statements

Theme/ sub-theme Meaning statement

1. Getting started

The processes taken and decisions that are made when getting

started in an activity that ultimately becomes sustained.

1.1. Choosing the right activity Having an interest in the activity and/or the activity matching the adolescent's capacity are important considerations when choosing what to do.

1.2. Getting the right fit Finding an activity that fits with the adolescent, the family and the facilitator.

1.2.1.It needs to be tailored Tailoring the activity to the capacity of adolescent in order for them to have achievable challenges.

1.2.2.It fits with our schedule

1.3. "Greasing the chute"

2. Wanting to succeed

2.1. Challenges and achievement

2.2. "Hoping to become big"

2.3. Being determined
Choosing an activity that fits with the schedules of the adolescent, family and facility.

Preparing for the activity to ensure adolescents have a smooth start, including background research and facilitation.

Some adolescents were driven to succeed at their activity.

Experiencing the challenges of the activity and gaining a sense of achievement.

Wanting to do better and be recognized.

Expressing commitment to the activity and rising to a challenge. 
3. A sense of belonging

3.1. Doing the same thing as everyone else

3.2. Being part of the club

3.3. The family belongs too

4. The coach is important

4.1. Getting the right coach

4.2. Coaching style

4.3. "More than a personal trainer"

5. Endorsement to continue

5.1. "I feel better if I'm fit and healthy"
The adolescent and/or their family gaining a sense of belonging from their participation in the activity.

Engaging in an activity that is seen as normal in the community.

Being integrated into the activity setting and having something in common with others.

Parents having a support network and opportunities to socialise with similar families.

The facilitator of the activity plays an important role in helping adolescents to continue participating in the activity.

Finding an understanding facilitator and the right person to help was important to parents.

Facilitators expressed going above and beyond their facilitating role to help the adolescent.

Meaningful relationships between the facilitator and adolescent were valued.

Personal and external factors that encourage and promote sustained participation.

Expressing a need to be fit and healthy to improve daily functioning now and into the future. 
5.2. The club helps me participate

5.3. Other people want me to succeed

6. Endorsement to support

6.1. The coach's reward

6.2. Benefits to the club

6.3. The family celebrating their child's success

7. Being passionate

7.1. Sport is my passion

7.2. Enjoying the activity

7.3. Our family loves sport
The activity occurs in an inclusive and accepting environment.

Perceptions that other people want the adolescent to succeed including family, professionals, facilitators and friends.

Factors that encourage those involved with the adolescent (e.g. facilitators, club and family) to continue supporting their participation in the activity.

The facilitator found helping the adolescent to be rewarding.

The facility becomes known as an inclusive facility and recognition brings rewards in the community.

Families experiencing pride and enjoyment from going to watch the activity together.

The adolescent's passion about sport or the particular activity encouraged them to get started and continue.

Finding a way to participate because of a love of sport.

Enjoying or being passionate about the particular activity.

The family values participation in sport.

Note: The word coach has been used to represent all facilitators of the activity. 